Research Papers

\title{
Effect of Nickel(II) ion on Copper Electrodeposition from Ethylenediamine Complex Bath
}

\author{
Hidetoshi ARIMURA a, b , Toshihiko SHIGEMATSU ${ }^{\mathrm{a}}$, Takaaki TSURUOKA ${ }^{\mathrm{c}}$, \\ Kensuke AKAMATSU ${ }^{c}$ and Hidemi NAWAFUNE ${ }^{\mathrm{c}, *}$
}

\begin{abstract}
${ }^{a}$ Graduate School of Science, Konan University (8-9-1, Okamoto, Higashinada-ku, Kobe-shi, Hyogo 658-8501)
${ }^{\mathrm{b}}$ Ishihara Chemical Co., Ltd. (5-26, Nishiyanagiwara-cho, Hyogo-ku, Kobe-shi, Hyogo 652-0806)

${ }^{\mathrm{c}}$ Frontiers of Innovative Research in Science and Technology (FIRST), Konan University (7-1-20, Minatojima-minami, Chuo-ku, Kobe-shi Hyogo 650-0047)

In the present paper, we describe direct copper electrodeposition on high resistivity substrates such as TiN and ITO from ethylenediamine complex bath. The copper electrodeposition was carried out at $1 \mathrm{~A} / \mathrm{dm}^{2}$ and $50{ }^{\circ} \mathrm{C}$. Smooth surface was obtained by adding thiodiglycolic acid. Good adhesion of deposited copper film on TiN was achieved from tape peeling test. Internal stress of deposited copper film from ethylenediamine complex bath was decreased by adding $5 \mathrm{mg} / \mathrm{L} \mathrm{NiSO}_{4} \cdot 6 \mathrm{H}_{2} \mathrm{O}$ in the bath. This bath could be used for the formation of copper wiring on high resistivity substrates as an alternative to conventional acidic copper sulfate bath.
\end{abstract}

Keywords : Copper Electrodeposition, Ethylenedimamine, ITO, Internal Stress

\section{Introduction}

Copper electrodeposition is used widely as a formation of interconnects metal in ultra large scale integration (ULSI), SiP, and $\mathrm{TSV}^{\left.1{ }^{-3}\right)}$. In those applications, the copper wirings were formed on silicon wafer with silicon dioxide insulated layer. However, copper diffuses easily into silicon and silicon dioxide and it reacts with silicon to form $\mathrm{Cu}_{3} \mathrm{Si}$ compounds at very low temperatures $\left(200^{\circ} \mathrm{C}\right)^{4)-6)}$. Therefore, high melting point materials such as $\mathrm{Ti}, \mathrm{Ta}, \mathrm{TiN}$, or TaN have been widely employed as conventional barrier materials to prevent inter-diffusion between copper layer and dielectric insulating layer. Since the barrier layer has high resistivity, copper seed layer prepared by physical vapor deposition (PVD) on barrier materials is also required for electrodeposition. However, PVD provides essentially poor step coverage and results in discontinuities in the copper film at the side wall of fine contact hole, trench and high aspect ratio via. Moreover, since typical acidic copper sulfate bath for copper interconnects has extremely strong acidity, the bath causes serious damage for some substrates.

Recently, few investigations have been studied on the direct copper electrodeposition on high resistivity substrate such as TiN and $\mathrm{TaN}^{7)-10)}$. Previously, direct copper electrodeposition on TiN from ethylenediamine complex bath (En-T bath) has been studied by our group ${ }^{11)}$. We have successfully achieved copper superfilling into contact hole from En-T bath.

As other attractive high resistivity substrate, the Indium-TinOxide (ITO) film is used widely as a formation of transparent conductive electrode for touch panel, display, and solar cell. PVD process has been used for the fabrication of minute copper pattern on ITO film. There exists a need to apply copper electrodeposition process for the fabrication of copper pattern on ITO for high reliability, low temperature, and low cost process. However, it is difficult to deposit directly copper film on ITO, because ITO

*E-mail: nawafune@center.konan-u.ac.jp film has high resistivity. Additionally, ITO film damages easily in strong acidity solution such as typical acidic copper sulfate bath ${ }^{12)-14)}$. Therefore, it is necessary to develop suitable electrodeposition bath for the fabrication of copper film on ITO. Those substrates for touch panel and solar cell are thin and warping easily by internal stress of deposited copper film. The warped substrate is also broken easily during handling. Therefore, regardless of annealing process for stress relaxation of as-deposited copper film after electrodeposition, control of internal stress of deposited copper film is necessary to apply electrodeposition process for the fabrication of copper wiring on high resistivity substrates.

In this report, we present direct copper electrodeposition on TiN and ITO from ethylenediamine complex bath under weak acidic condition $(\mathrm{pH}=5.0)$. X-ray diffraction $(\mathrm{XRD})$ analysis was performed for characterization of the crystallite size, and ununiform distortion of the deposited film. Influence of nickel (II) ion on internal stress of obtained copper film was also investigated.

\section{Experimental Section}

\section{1 Materials}

All chemicals, copper (II) sulfate pentahydrate $\left(\mathrm{CuSO}_{4} \cdot 5 \mathrm{H}_{2} \mathrm{O}\right)$, ethylenediamine, $\left(\mathrm{NH}_{4}\right)_{2} \mathrm{SO}_{4}$, glycine, thiodiglycolic acid (TDG), nickel(II) sulfate hexahydrate $\left(\mathrm{NiSO}_{4} \cdot 6 \mathrm{H}_{2} \mathrm{O}\right), 98$ mass $\%$ sulfuric acid $\left(\mathrm{H}_{2} \mathrm{SO}_{4}\right)$, and 10 mass\% Ammonia soution $\left(\mathrm{NH}_{4} \mathrm{OH}\right)$ were analytical grade and used as received. Distilled water was used for the preparation of all aqueous solutions and washing steps. TiN (thickness: $100 \mathrm{~nm}$ ) and ITO film (thickness: $80 \mathrm{~nm}$ ) are deposited on $\mathrm{SiO}_{2} / \mathrm{Si}$ wafer and glass substrate by physical vapor deposition (PVD), respectively. $\mathrm{TiN} / \mathrm{SiO}_{2} / \mathrm{Si}$ and ITO film were used as substrates for all experiments.

\section{2 Copper electrodeposition on TiN and ITO}

En-T bath contains $0.1 \mathrm{~mol} / \mathrm{L} \mathrm{CuSO}_{4} \cdot 5 \mathrm{H}_{2} \mathrm{O}, 0.3 \mathrm{~mol} / \mathrm{L}$ ethylenediamine, $1.5 \mathrm{~mol} / \mathrm{L}\left(\mathrm{NH}_{4}\right)_{2} \mathrm{SO}_{4}, 0.3 \mathrm{~mol} / \mathrm{L}$ Glycine, and $2 \mathrm{mg} / \mathrm{L}$ Thiodiglycolic acid. $\mathrm{NH}_{4} \mathrm{OH}$ or $\mathrm{H}_{2} \mathrm{SO}_{4}$ was added into 
En-T bath to adjust the $\mathrm{pH}$ to 5.0. Copper electrodeposition were carried out at $1 \mathrm{~A} / \mathrm{dm}^{2}$ and $50{ }^{\circ} \mathrm{C}$ on TiN and ITO substrate. As a control experiment, acidic copper sulfate bath containing 0.1 $\mathrm{mol} / \mathrm{L} \mathrm{CuSO}_{4}$ and $0.3 \mathrm{~mol} / \mathrm{L} \mathrm{H}_{2} \mathrm{SO}_{4}$ were also used for electrodeposition on TiN and ITO. Obtained copper films were observed by optical and scanning electron microscope (SEM). Thickness of deposited copper film is analyzed by X-ray fluorescence (XRF) spectroscopy to investigate copper deposition rate. Adhesion between deposited copper film and substrate are evaluated by tape peeling test (JIS standard, K-5600-5-6).

\section{3 Evaluation of internal stress}

The internal stress of deposited copper film from En-T bath was measured by bent strip technique. Copper electrodeposition on $0.077 \mathrm{dm}^{2}$ test strip (copper alloy) from En-T bath with 0 , $1,2,5$, and $10 \mathrm{mg} / \mathrm{L} \mathrm{NiSO}_{4} \cdot 6 \mathrm{H}_{2} \mathrm{O}$ were carried out at $1 \mathrm{~A} / \mathrm{dm}^{2}$ and 105.5 coulomb (C). The degree of legs-spread of test strip after electrodeposition were measured by deposit stress analyzer (Specialty testing and Development Co. PN683). The internal stress of deposited copper film was calculated from the length of spread. If the test strip legs are spread outward on the side that has been plated (plated side out and resist side in) the deposit stress is tensile in nature. If the test strip legs are spread inward on the side that has been plated, the deposit stress is compressive in nature.

\section{4 Characterization}

XRD analysis was performed for characterization of the crystallite size, ununiform distortion and orientation index calculated from Scherrer formula and Stokes and Wilson formula. The measurement of electrical resistivity for the copper films was carried out at room temperature by using four-point probes. Concentration of nickel in deposited copper films was measured by inductively coupled plasma - atomic emission spectrometry (ICPAES).

\section{Results and Discussion}

\section{1 Direct copper electrodeposition on TiN and ITO}

Electrical conductivity of TiN and ITO were $10.04 \times 10^{5} \mathrm{~S} / \mathrm{m}$ and $5.91 \times 10^{5} \mathrm{~S} / \mathrm{m}$, respectively. Polarization resistance of En-T bath and acidic copper sulfate bath were investigated by previous report ${ }^{11)}$. Fig. 1 shows SEM image of deposited copper film on TiN. Minute and smooth copper film was deposited on TiN from En-T bath. On the other hand, although granular copper was deposited on TiN, uniform copper film was not formed on TiN from acidic copper sulfate bath ${ }^{15)}$. Fig. 2 shows photograph of deposited copper film on ITO from En-T bath. The bright copper film was deposited on ITO. The surface molphology of copper

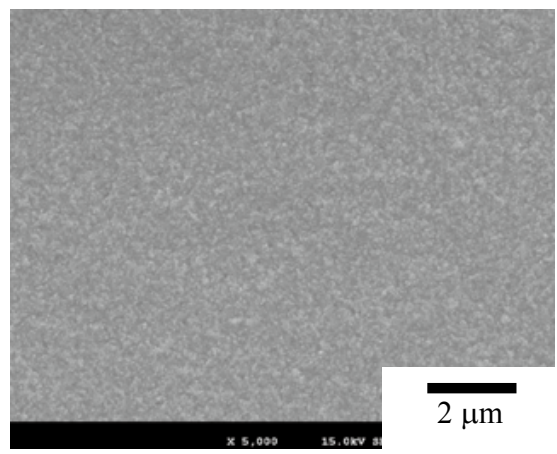

Fig. 1 SEM image of deposited copper film on TiN from En-T bath film on ITO was smooth similarly to that of the film deposited on TiN. Adhesion between deposited copper film (thickness: $1 \mu \mathrm{m}$ ) and substrate are evaluated by tape peeling test. Good adhesion of deposited copper film on TiN was achieved, whereas a part of copper film on ITO was peeled off from substrate. To improve the adhesion between copper film and ITO, chromium was deposited on ITO film by sputtering process prior to copper electrodeposition. Adhesion of copper film on ITO was improved by the interposition of sputtered chromium layer (results not shown). Copper film was not formed on chromium coated ITO film from acidic copper sulfate bath. Copper deposition rate on TiN and ITO from En-T bath were calculated from the thickness of deposited copper film measured by XRF. Fig. 3 shows distance dependence of copper deposition rate from electric contact point. Copper deposition rate is found to decreases as the distance from contact point increases. There were no significant differences in copper deposition rate at each point for TiN and ITO substrates.

\section{2 Influence of nickel(II) ion on internal stress}

Copper electrodeposition on test strip from En-T bath containing $0,1,2,5$, and $10 \mathrm{mg} / \mathrm{L} \mathrm{NiSO}_{4} \cdot 6 \mathrm{H}_{2} \mathrm{O}$ was carried out at $1 \mathrm{~A} / \mathrm{dm}^{2}$ and 105.5 coulomb (C). The legs of test strip in which copper deposited on it spread inward. Compressive stress was observed from the inward spread of test strip legs after electrodeposition from En-T bath with and without $\mathrm{NiSO}_{4} \cdot 6 \mathrm{H}_{2} \mathrm{O}$. Fig. 4 shows changes in internal stress of deposited copper films from En-T bath with $0,1,2,5$, and $10 \mathrm{mg} / \mathrm{L} \mathrm{NiSO}_{4} \cdot 6 \mathrm{H}_{2} \mathrm{O}$. The internal stress of deposited copper film from En-T bath $\left(\mathrm{NiSO}_{4} \cdot 6 \mathrm{H}_{2} \mathrm{O}\right.$ : $0 \mathrm{mg} / \mathrm{L}$ ) was $30.5 \mathrm{MPa}$. The internal stress of deposited copper film decreased gradually with increasing concentration of $\mathrm{NiSO}_{4} \cdot 6 \mathrm{H}_{2} \mathrm{O}$. The minimum internal stress of deposited cop-

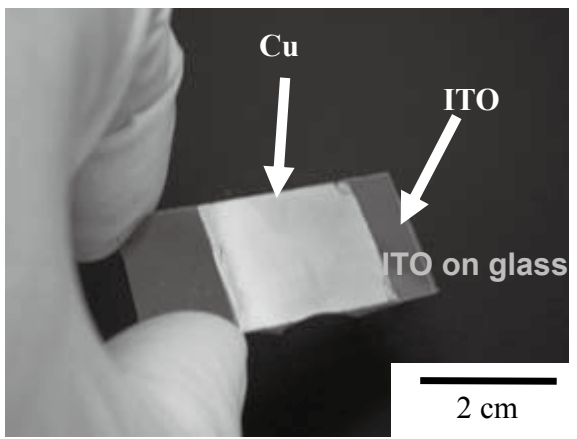

Fig. 2 Deposited copper film on ITO from En-T bath.

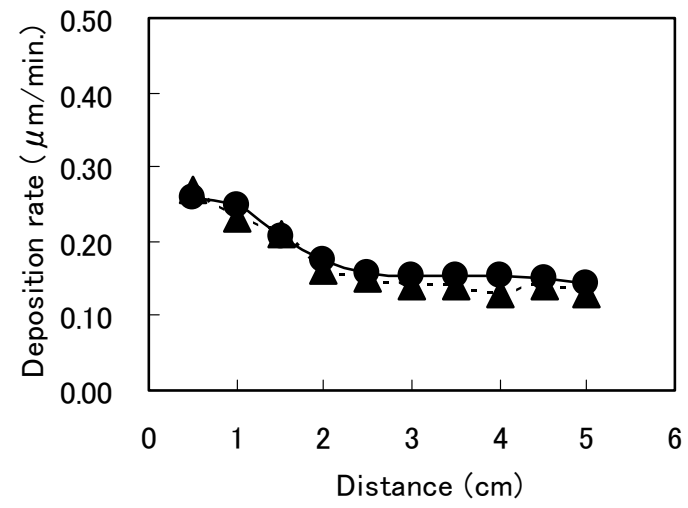

Fig. 3 Distance dependence of copper deposition rate from electric contact: 0 on TiN, and $\boldsymbol{\Delta}$ ITO. 
per film was $21.1 \mathrm{MPa}$, in the case that the concentration of $\mathrm{NiSO}_{4} \cdot 6 \mathrm{H}_{2} \mathrm{O}$ was $5 \mathrm{mg} / \mathrm{L}$ in En-T bath. This result indicates that internal stress of copper film could be controlled by adding small amount of $\mathrm{NiSO}_{4} \cdot 6 \mathrm{H}_{2} \mathrm{O}$.

Fig. 5 shows changes in XRD patterns of as-deposited and heat-treated copper film from En-T bath with $\mathrm{NiSO}_{4} \cdot 6 \mathrm{H}_{2} \mathrm{O}$. The XRD pattern of as-deposited copper film from En-T bath showed weak peaks. Compared with XRD pattern of as-deposited copper film from En-T bath, the (111) peaks of as-deposited copper film from En-T bath with 2 and $5 \mathrm{mg} / \mathrm{L} \mathrm{NiSO}_{4} \cdot 6 \mathrm{H}_{2} \mathrm{O}$ were intense. It is indicated that the sharp and intense (111) peaks of as-deposited copper film cause low ununiform distortion of the film. As a result, it seems that internal stress of the film was decreased, since deposited copper film has low ununiform distortion. As shown in Fig. 5 -e), f), g), and -h), the sharp and intense diffraction peaks were observed for all copper films heat-treated

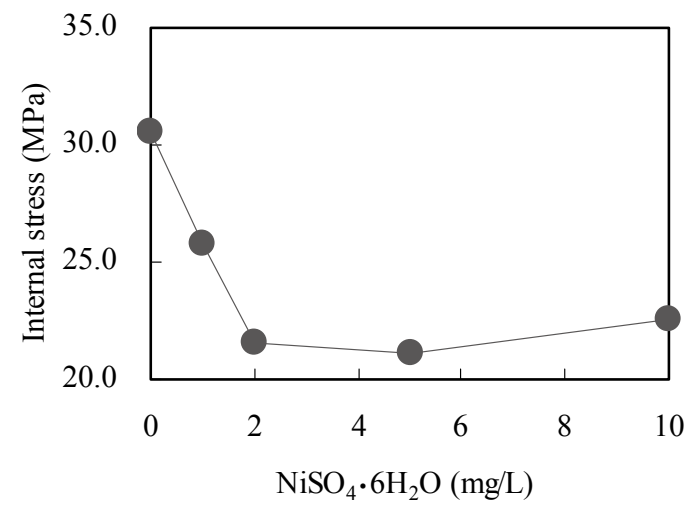

Fig. 4 Changes in internal stress of deposited copper films from En-T bath with addition of $\mathrm{NiSO}_{4} \cdot 6 \mathrm{H}_{2} \mathrm{O}$.

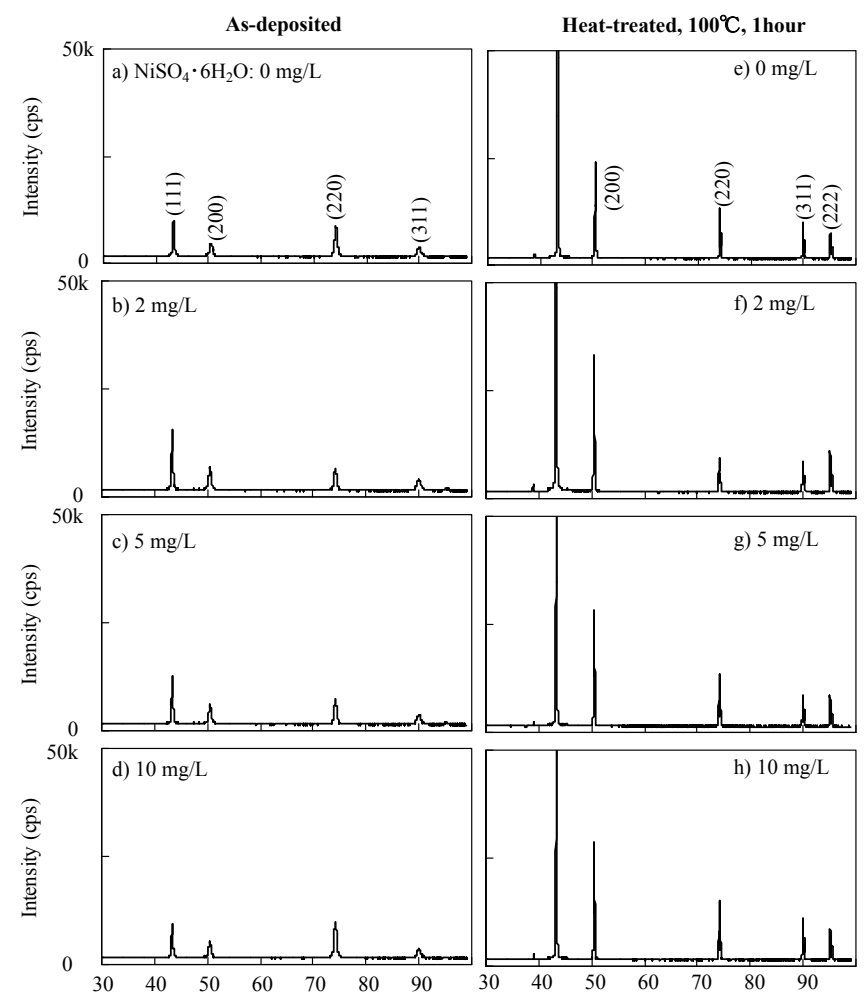

Fig. 5 Changes in XRD patterns of as-deposited and heat-treated copper film from En-T bath with $\mathrm{NiSO}_{4} \cdot 6 \mathrm{H}_{2} \mathrm{O}$. in boiled water for 1 hour. Fig. 6 shows changes in orientation index of as-deposited and heat-treated copper film from En-T bath with $\mathrm{NiSO}_{4} \cdot 6 \mathrm{H}_{2} \mathrm{O}$. The preferred orientation of as-deposited copper films were (220) peak. After heat-treated in boiling water for 1 hour, face centered cubic (fcc) structure with (111) preferred orientation were identified. Fig. 7 shows changes in crystallite size of as-deposited and heat-treated copper film from
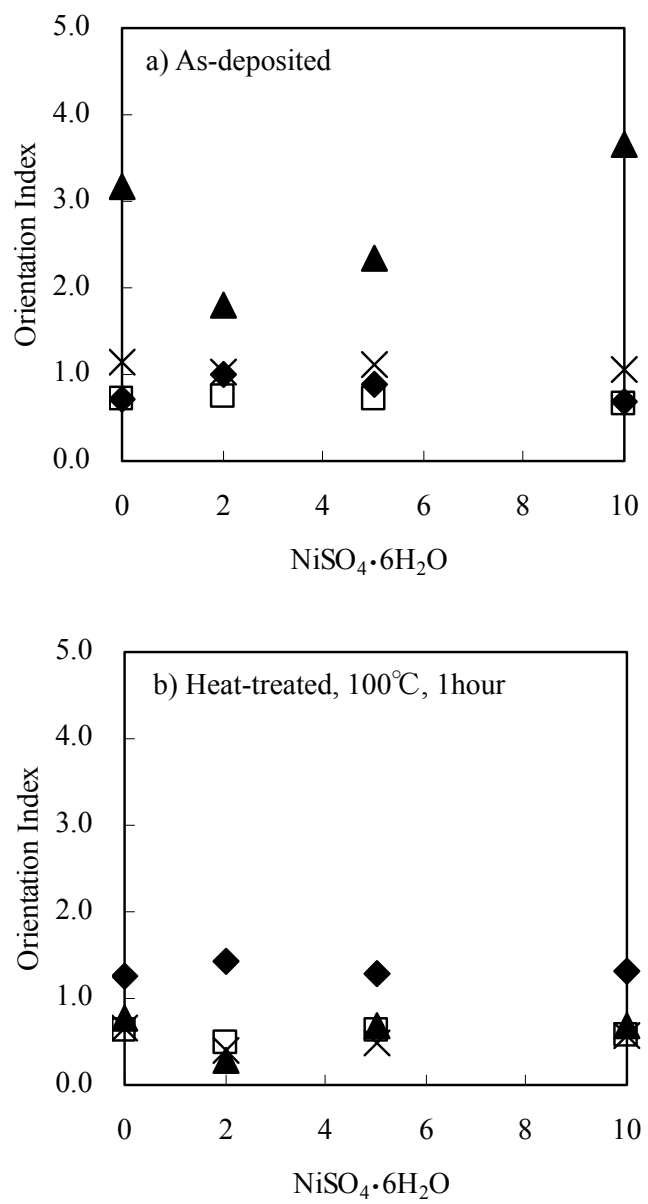

Fig. 6 Changes in orientation index of a) as-deposited, and b) heat-treated copper film from En-T bath with addition of $\mathrm{NiSO}_{4} \cdot 6 \mathrm{H}_{2} \mathrm{O}:>(111), \square(200), \boldsymbol{\Delta}(220)$, and $\times(311)$.

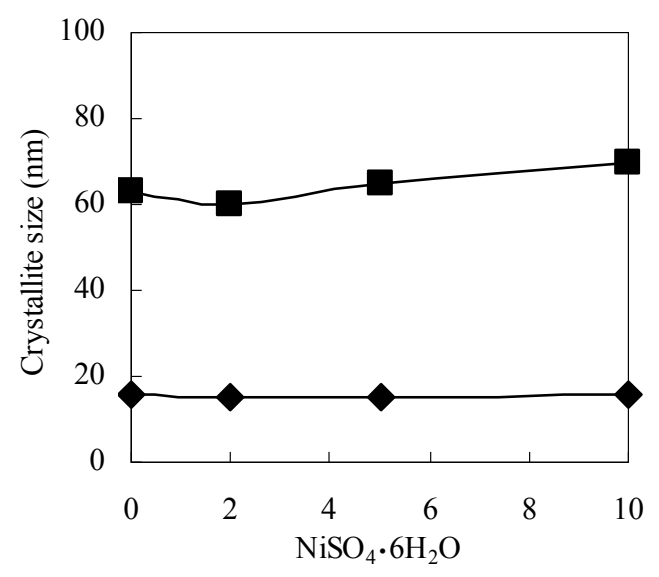

Fig. 7 Changes in crystallite size of deposited copper film from En-T bath with addition of $\mathrm{NiSO}_{4} \cdot 6 \mathrm{H}_{2} \mathrm{O}:$ as-deposited, and $\square$ heattreated in boiling water for 1 hour. 


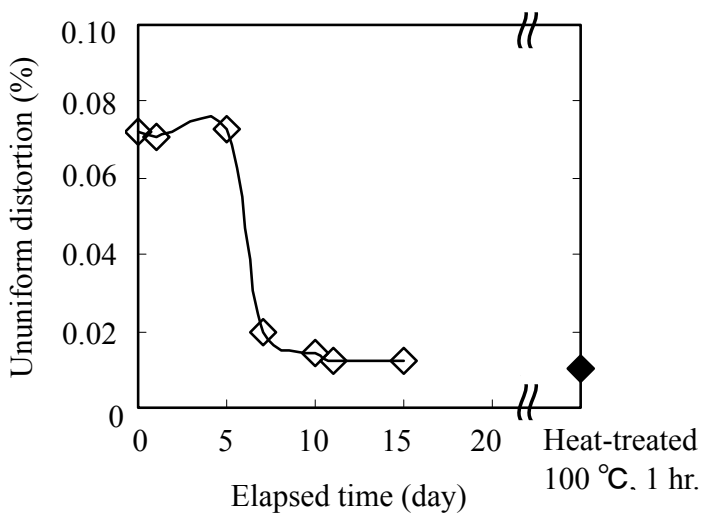

Fig. 8 Changes in ununiform distortion of copper films with elapsed time at room temperature and heat-treated in boiling water for 1 hour from En-T bath with $5 \mathrm{mg} / \mathrm{L}$ of $\mathrm{NiSO}_{4} \cdot 6 \mathrm{H}_{2} \mathrm{O}$.

En-T bath with $\mathrm{NiSO}_{4} \cdot 6 \mathrm{H}_{2} \mathrm{O}$. The crystallite size of as deposited copper films were approximately $15 \mathrm{~nm}$. The crystallite size of deposited copper films were increased to approximately $60 \mathrm{~nm}$ by heat-treated in boiling water for 1 hour. Fig. 8 shows changes in ununiform distortion of copper film with elapsed time at room temperature and heat-treated in boiling water for 1 hour. Ununiform distortion of as-deposited copper films from En-T bath with 0 and $5 \mathrm{mg} / \mathrm{L} \mathrm{NiSO}_{4} \cdot 6 \mathrm{H}_{2} \mathrm{O}$ were $0.08{ }^{15)}$ and $0.07 \%$, respectively. Ununiform distortion of deposited copper film from En-T bath drastically decreases upon elapsed time, and the value was less than $0.03 \%$ after 7 days ${ }^{15)}$. On the other hands, ununiform distortion of deposited copper film from En-T bath with $5 \mathrm{mg} / \mathrm{L}$ $\mathrm{NiSO}_{4} \cdot 6 \mathrm{H}_{2} \mathrm{O}$ was $0.02 \%$ after 7 days. In general, since decrease of ununiform distortion for metallic film causes decrease of internal stress, it appears that the decrease of ununiform distortion of copper film deposited from En-T bath with $5 \mathrm{mg} / \mathrm{L} \mathrm{NiSO}{ }_{4} \cdot 6 \mathrm{H}_{2} \mathrm{O}$ causes the decrease of compressive stress.

In order to confirm existence of nickel in deposited copper film, ICP-AES measurement was carried out. Concentration of nickel in all the copper films deposited from En-T bath with 0, 1, 2,5 , and $10 \mathrm{mg} / \mathrm{L} \mathrm{NiSO}{ }_{4} \cdot 6 \mathrm{H}_{2} \mathrm{O}$ were less than detection limits of ICP-AES. In general, contamination of nickel in deposited copper film causes increasing of resistivity. The resistivity of copper film obtained from En-T bath containing $\mathrm{NiSO}_{4} \cdot 6 \mathrm{H}_{2} \mathrm{O}$ were measured by four-point probes. As shown in Fig. 9, the resistivity of all copper films obtained were less than $2 \mu \Omega \cdot \mathrm{cm}$, which is suitable for electronic devices. The result of XRD measurement indicates that crystallite structure of deposited copper film from En-T bath was changed slightly by adding small amount of nickel (II) ion in the bath. Since the nickel signals were not detectable in ICP measurement for samples obtained after deposition of copper for several minutes, the extremely small amount of nickel ions (or atoms) may be adsorbed on copper surface and plays a role for determining crystalline structures of the deposited copper film. However further experimental study is necessarily to verify this assumption and the effort is currently underway. The results will be published elsewhere.

\section{Conclusion}

Direct copper electrodeposition on high resistivity substrates

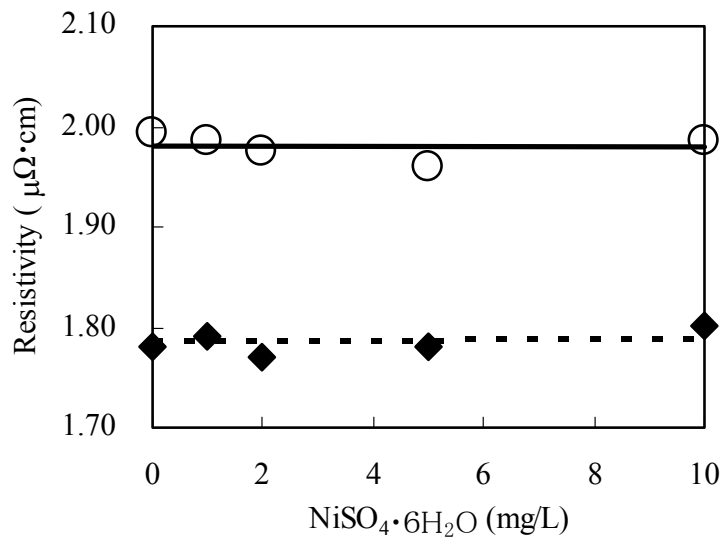

Fig. 9 Changes in resistivity of deposited copper films from En-T bath with addition of $\mathrm{NiSO}_{4} \cdot 6 \mathrm{H}_{2} \mathrm{O}: \bigcirc$ as-deposited, and heat-treated in boiling water for 1 hour.

such as TiN and ITO were successfully achieved from ethylenediamine complex bath. Smooth and minute copper film was obtained from En-T bath. Internal stress of deposited copper film was controlled by adding small amount of $\mathrm{NiSO}_{4} \cdot 6 \mathrm{H}_{2} \mathrm{O}$ in En-T bath. The resistivity of the film was nearly agreement with the bulk copper, which is suitable for electronic devices. The bath could be used for the formation of copper wiring on high resistivity substrates as an alternative to conventional acidic copper sulfate bath.

(Received August 262011 ; Accepted November 21, 2011)

\section{References}

1) D. Edelstein, J. Heidenreich, R. Goldblatt, W. Cote, C. Uzoh, N. Lustig, P. Roper, T. McDevittt, W. Motsifft, A. Simon, J. Dukovic, R. Wachnik, H. Rathore, R. Schulz, L. Su, S. Lucet, J. Slatteryt. Edelstein, J. Heidenreich ; IEDM 1997 Technical Digest, 773 (1997).

2) M. Motoyoshi ; Proceedings of the IEEE, 97, (1), 43 (2009).

3) J.U. Knickerbocker, P.S. Andry, B. Dang, R.R. Horton, C. S. Patel, R.J. Polastre, K. Sakuma ; ECTC 2008, 538 (2008).

4) S. H. Corn, J. L. Falconer, A. W. Czanderna ; J. Vac. Sci. Technol., A6, 1012 (1988).

5) A. Cros, M. O. Aboelfotoh, K. N. Tu ; J. Appl. Phys., 67, 3328 (1990).

6) K.-M. Chang, T.-H. Yeh, I-Chung Deng, C.-W. Shih ; J. Appl. Phys., 82, 1469 (1997).

7) A. Radisic, J. G. Long, P. M. Hoffmann, P. C. Searson ; J. Electrochem. Soc., 148, (1), C41 (2001).

8) A. Radisic, Y. Cao, P. Taephaisitphongse, A. C. West, P. C. Searson ; J. Electrochem. Soc., 150, (5), C362 (2003).

9) L. Graham, C. Steinbrüchel, D. J. Duquette ; J. Electrochem. Soc., 149, (8), C390 (2002).

10) S. Kim, D. J. Duquette ; J. Electrochem. Soc., 153, (6), C417 (2006).

11) H. Nawafune, H. Kitamura, S. Mizumoto, E. Uchida, T. Okada ; Hyomen Gijutsu, 51, 1142 (2000).

12) T. Oyama ; J. Surf. Finish. Soc. Jpn., 60, 616 (2009).

13) H. Takahashi ; J. Surf. Finish. Soc. Jpn., 60, 622 (2009).

14) S. Takagi ; J. Vac. Soc. Jpn., 50, (2), 31 (2007).

15) H. Arimura, T. Tsuruoka, K. Akamatsu, H. Nawafune ; J. Surf. Finish. Soc. Jpn., 62, 448 (2011). 